\title{
Conclusion: the restorative city - a challenge about means and ends
}

\author{
Chris Straker ${ }^{*}$
}

\section{Introduction}

These Notes from the Field explore the concept of the restorative city, in six different settings, offering examples of present practice as well as raising questions about future developments. Whilst they share some common characteristics, all of the cities have developed in ways that also reflect their context. As Mannozzi states in the introduction, to 'promote a restorative city is a challenge: there are no available standards or guidelines to follow'. The decision to move a city in this restorative direction is being done by pioneers without any consistently tested road map to follow - in terms of either coherent structural constructs or philosophical underpinning theories and there has been very little research into the concept (Green, Johnstone \& Lambert, 2013, 2014; Straker, 2014). This publication is not an attempt to offer a specific model, or road map, for others to follow, but provides reflections from those undertaking this innovative work at the start of their restorative city journey.

In 2010 Hull, a city in the north of England, declared itself to be the first restorative city at the IIRP World conference, ${ }^{1}$ held within the city. This was a rather presumptuous statement but reflected a decision by advocates in Hull, borne out of the developing practice in the city, to explicitly state restorative justice could be more than simply a process aligned with criminal justice. As Green et al. (2013: 1-2) state, discussing restorative work in Hull,

as knowledge and awareness of restorative justice has grown, so too has its application ... a new stage in the evolution of restorative justice as it moves beyond the repair of harm caused by criminal conduct to addressing problems in schools, social services, workplaces, and neighbourhoods.

The development towards the new paradigm of a restorative city would suggest a rejection of the existing patriarchal paradigm of city governance and existing pat-

* Chris Straker is a director, trainer and consultant at Restorative Thinking Ltd. (www.restorativethinking.co.uk) and a freelance restorative trainer registered with the Restorative Justice Council, UK.

Contact author: strakerchris@me.com.

1 International Institute for Restorative Practices, https://iirp.edu/news/welcome-to-hull-theworld-s-first-restorative-city-site-of-the-2010-iirp-world-conference-restorative-practicesacross-disciplines. 
terns of engagement with individuals, groups and communities. The collection in this Notes from the Field gives a space for six different cities, who believe that restorative 'processes have applicability to all areas of our lives' (Sullivan \& Tifft, 2010: 93), to share the thinking behind their decision to become restorative cities, and the lessons they learnt from their efforts.

\section{Origins}

All of the cities have developed their restorative city models under different conditions and in reaction to different triggers. But all started with a group, or groups of professionals, agencies and practitioners coming together to respond to a perceived need within their communities; and all were working in communities where restorative justice was already established to some degree, 'to step up the coordination of work already under way in the region' (Como). This step towards becoming an explicit restorative city was an attempt, in all cases, to find a strategic approach to restorative working to meet the needs of the whole community in which the projects were set. As Tempio Pausania said, it was 'an opportunity to establish a cultural change: trying to create a restorative city ... to give back to the community the ability to manage and resolve conflicts'.

\section{Theoretical and conceptual basis}

As has already been noted, there is, at this time, no consistent definition of what a restorative city is. This is a strength of the concept, but it also offers potential risks. It is a strength because it reflects the context in which each city is developing its model, allowing each to develop based on its own realities, but also poses the risk that bogus claims for being a restorative city could be made if there is no consensus on what it is.

Mannozzi, in the introduction, suggests nine 'essential elements' to designing a restorative city, but across the six cities there is no consistently concrete set of elements on which they have each built their projects. All of the cities need to develop clarity with regard, not only to their principles and values, but also on the objectives they intend to achieve.

Without clear and explicit underpinning language about principles and practice all of the projects could risk, unintentionally, re-creating 'the forms of symbolic violence ... that [they have] sought to oust' (Green et al., 2014: 45).

While all of the cities talk about basing their visions on restorative principles - a commitment in general terms to work 'WITH' in relation to engaging with organisations and communities - there is no consistency on what, or which, principles they are evoking. Whanganui states,

The Trust wanted to dispel the idea, prevalent at the time that the restorative approach was only applied when there was conflict or harm done. It wanted to promote the idea of a community ... To build social capital in order to produce a resilient community that could manage diversity and conflict within it. 
But Leuven, after initial discussions decided that, 'the focus of the project should be on "dealing with conflict" and not [only] on "social cohesion" as such'.

Tempio Pausiana went furthest by breaking down its objectives and the processes into tiers of activity to create: 'a model of community that promotes lifestyles and conflict management marked by responsibility, peace and well-being'. But its statement that, we 'adopt a positive view of persons and context because we think that restorative practices are the best way to activate positive resources in people and their environments' requires a clearer explanation of what it is restorative practices offers to do in a way that improves on existing systems.

The importance of all of the cities having more clarity about their values and what they intend to achieve, within their own very specific context, will be important in protecting them from the hurdle highlighted by Pavlich (citing Derida) when he says:

The paradox in the instituting moment of an institution is that, at the same time that it starts something new, it also continues something ... it must to some extent break with the past, keep the memory of the past, while incorporating something absolutely new (2005: 120).

To create a restorative city there is a requirement to have a clear sense of where restorative approaches fit within existing contexts, and what impact that existing context will have on its development. There must be a plan for a future that acknowledges the dynamics that could help or hinder its implementation. It is in this area that all of the project cities need to reflect.

\section{Operationalisation}

This self-understanding, of context, allied to a clear idea on what it wants restorative working to achieve, must be the starting point for the operationalisation of the projects through their activities and structures they build for delivery. Woolford (2009: 11) supports this view when he says,

such a project would require more than just platitudes and good ideas; it would require a politics - a strategic plan for countering the current arrangements of social power - to challenge entrenched and dominant notions.

All of the projects started by identifying key individuals, groups or organisations to engage with to deliver the project. Brighton described this as,

the [identification of] identified key stakeholders from a range of agencies to form a strategic group to act as a critical friend and to help steer the direction of the project.

There was also a sense that there needed to be a connection to communities and community groups to ensure they are engaged at the start. The logistics of this 
are complex, but the intent was to engage and develop participation in this process, wherever possible.

There were concrete examples of other strategies and planning phases in all of the cities. Whanganui, for instance, looked to ensure that leaders in the city adopted restorative behaviours in their meetings and exemplified restorative working through policies within the council. This was then broadened into practice in working around domestic, family and housing issues. They have a clear desire to change the culture of the organisations that run the city, as well as the way they interact with communities.

Leuven stated that they wanted to ensure that

the people running the project did not proclaim themselves to be external experts or specialists with the task of untangling problematic issues or situations of conflict, but rather as facilitators of opportunities for meetings and dialogue between the parties involved.

The spirit of this was evident through the thread of deliberative democracy that ran through all of the projects as a belief in the importance of 'citizen agency' (Dzur, 2015: 52).

Clarijs and Malmberg (2012: 9) describe what this would look like in practice when they say that:

In this state citizens take back their responsibilities, steer their own process, resolve with whom they want to cooperate and decide their own solutions ... This transition implies a repositioning for governments and professional organisations.

The challenge for all of the cities in these Notes from the Field, is for them to reflect on to what degree they are, unintentionally, now, working in (new) silos: doing interesting and important work, changing culture, enabling individuals and groups to engage in their own solutions for conflict and building relations but, that outside of the scope of the project, other citizens are not aware of a change, or a 'new' way of working. There must be a constant reflection on the power dynamics being created between those 'leading' the projects and the citizens of communities and cities they are engaging with. This is especially so around how restorative city 'agents' communicate about the projects in terms of activity, objectives, outcomes and engagement.

\section{Ongoing processes}

There was a consciousness across the cities best summed up by Brighton, that

it is important that the restorative city concept is grounded in planning that has clear outcomes but also reflects the needs of citizens. It also, through 
cross-agency working groups, tries to ensure that all parts of the city are talking to each other and sharing values and behaviours.

This approach echoes Beck (2012: 392) who states that restorative approaches working in the community, 'support activities [that] build and strengthen community institutions, they also can foster human connections'.

The conscious efforts to link working groups with practitioners, other professionals and academics was built into all of the projects. Leuven noted that the

project helped raise awareness and improve knowledge of restorative justice ... changing the views on conflict, damage, restoration, victims and offenders of those involved in training sessions and other project activities. Furthermore, the project helped improve social relationships in the contexts where it intervened.

The models of evaluation of the individual projects, though, was inconsistent. There is a need to ensure that cities are able to provide quantitative and qualitative evidence of success. Wonshé (2004: 258) takes this further and says, 'I think it is imperative to evaluate programs on their understanding of fundamental restorative justice principles and not assume these programs are ideal because they exist'. The focus of research also has to ensure that it does not 'ignore how people experience the introduction of restorative values ... and what they do when it goes wrong' (Green et al., 2014: 44).

\section{Conclusions and findings}

The concept of the restorative city is a courageous aspiration and all of the cities in these Notes from the Field have had different starting points and methodologies that reflect their context. The process by which cities can move away from the existing paternalistic paradigm, and create their own restorative building blocks of what the city landscape, in ideas and structures, will look like, is only just being explored.

In moving forward, it is evident that the process of becoming a restorative city needs to have: clear principles and values guiding practice; a strategy that embraces all tiers of organisations; the engagement, empowerment and participation of families as a priority; and the identification and analysis of quantitative, as well as qualitative, data.

Brighton has looked to develop a clear city-wide strategy, tested by the external quality marks that exist in England and Wales; Bristol, also like Brighton, has looked to gather existing restorative initiatives into a more coherent whole. Both look to ensure that the restorative city is, not only about enabling professionals, but is also about developing opportunities, context and the skills for individual citizens, groups and communities to be active participants.

Tempio Pausiana have developed tools to look at integration across their work so that they do not repeat the power dynamics of existing paternalistic 
paradigms. Como echoes this view when it states that it is important for the restorative city to not create groups who 'proclaim themselves to be external experts or specialists', but explicitly look for the network of relationships that is guided by a WITH mentality. As Leuven stated, there is a need to create 'more sectional and cross-sectional exchange about restorative ways of handling conflicts'.

Restorative practice should actively be aiming to build up communities through developing strong relationships. Its focus on empathy - understanding the 'other' - challenges divisive rhetoric. It sees communities within cities, not as an excluding concept, but as a series of overlapping, shifting groupings where fragmentation into cliques around sexuality, gender, class, race and religion is reduced. This encourages dialogue that leads to understanding which focuses on solutions rather than barriers. It opens up the space, where necessary, for conflict to be dealt with in a positive way. In short, it changes the passive nature of the relationship between the individual and the state.

Restorative working at a local authority level needs to be more than just a utopian goal, it needs to deliver outcomes that improve the lives of families and the professionals who work with them. It has to be robust in its challenge to the traditional paradigm of local government working, by understanding that it is developing in the context of dominant neo-liberal political economy that demands proof and value for money. It is, therefore, essential that those embarking on developing restorative cities, and that includes those in this collection, are clear on their objectives and the outcomes they want to achieve. They also need to be able to demonstrate impact if the idea is to avoid being marginalised.

Finally, as Whanganui states,

a restorative city is an aspirational vision and may never be fully realised. However, it is the conversations, connections and relationships made on the way that drives the Trust to keep working towards creating the environment for Whanganui people to thrive and succeed together through respectful relationships.

The examples in this journal issue offer ideas for those who are looking to create their own restorative cities. There is still work to be done around definition, values, the physical landscape of restorative cities, the engagement of all parts of the community and the relationship of the parts to the city towards each other and in relation to a wider national context. 'Bringing all the initiatives together to learn from each other was detected as a strong need' by Leuven.

There is a need to make a determined effort for the idea of the restorative city to extend beyond the enthusiastic advocates of restorative working and find its place in the thinking of those responsible for the strategic planning for all cities by creating more 'visibility in society by spreading stories and developing a communication strategy' (Leuven). The challenge is to make the case for a different way of being that the concept of the restorative city could offer, and it is hoped that this collection will add to the present debate on this subject. 


\section{References}

Beck, E. (2012). Transforming communities: restorative justice as a community building strategy. Journal of Community Practice, 20(4), 380-401. doi: 10.1080/10705422.2012.732003.

Dzur, A.D. (2015). Public restorative justice: the participatory democratic dimensions of institutional reform. Raisons Politiques, 3(59), 51-71. doi:10.3917/rai.059.0051.

Clarijs, R. \& Malmberg, T. (2012). Introduction. In R. Clarijs \& T. Malmberg (eds.), The quiet revolution: aggrandising people power by family group conferences (pp. 7-10). Amsterdam: SWP Publishing.

Green, S., Johnstone, G. \& Lambert, C. (2013). What harm, whose justice? Excavating the restorative movement. Contemporary Justice Review, 16(4), 445-460. doi: 10.1080/10282580.2013.857071.

Green, S., Johnstone, G. \& Lambert, C. (2014). Reshaping the field: building restorative capital. Restorative Justice: an International Journal, 2(1), 43-63. doi: 10.5235/20504721.2.1.43.

Pavlich, G. (2005). Governing paradoxes of restorative justice. London: Glasshouse Press. Sullivan, D. \& Tifft, L. (2010). Restorative justice: healing the foundations of everyday lives (2nd ed.). Boulder: Lynne Rienner Publishers.

Straker, C. (2014). The restorative city: emperor's new clothes or achievable paradigm shift? (Unpublished MA Dissertation). University of Hull, England.

Wonshé. (2004). How does the 'who, what, where, when' affect the practice of restorative Justice? In H. Zehr \& B. Toews (eds.), Critical issues in restorative justice (pp. 253-263). Monsey: Criminal Justice Press.

Woolford, A. (2009.) The politics of restorative justice: a critical introduction. Black Point Nova Scotia: Fernwood Publishing. 